\title{
LA INMIGRACIÓN LATINA EN ASHEVILLE, CAROLINA DEL NORTE: UNA VISTA DESDE ADENTRO. LA AUTOETNOGRAFÍA COMO METODOLOGÍA PARA EL ANÁLISIS MIGRATORIO
}

\author{
Geny HeRnÁNDEZ López \\ Universitat Rovira i Virgili \\ Doctorado en Antropología y Comunicación \\ geny.hernandez@estudiants.urv.cat
}

RESUMEN: El presente artículo se divide en dos partes, en la primera se discuten los conceptos de la autoetnografía como recurso metodológico para realización del análisis antropológico de la inmigración desde la mirada activa y participativa de la autora - sin por esto dejar de ser objetiva - y los conceptos de movilidad e inmovilidad y su relación con la migración. En la segunda parte se narra la situación de la inmigración de origen latinoamericano en la ciudad de Asheville, Carolina del Norte, y su relación con el movimiento por los derechos de los inmigrantes en esa comunidad, el reconocimiento a las organizaciones comunitarias que apoyan dicho movimiento $y$ su devenir ante la adversidad.

PALABRAS CLAVE: autoetnografía; inmigración; Asheville; movimiento proinmigrante; movilidad e inmovilidad. 
ABSTRACT: This article is divided into two parts. The first discusses the concepts of auto-ethnography as a methodological resource for the anthropological analysis of immigration from the active and participatory view of the author-without ceasing to be objective- and the concepts of mobility and immobility and their relationship with migration. The second part discusses Latin American immigration in the city of Asheville, North Carolina, and its relationship with the movement for the rights of immigrants in that community, the recognition of community organizations that support that movement and its evolution in the face of adversity.

KEYWORDS: auto-ethnography; immigration; Asheville; pro-immigrant movement; mobility and immobility. 


\section{La autoetnografía como modelo metodológico en la antropología'}

Hace casi cincuenta años que Scholte (Okely, 1992: 1) abrió la puerta a la importancia de la etnografía en la antropología y de la relevancia de la voz del etnógrafo dentro de la narrativa:

El trabajo de campo y el análisis subsiguiente constituyen una praxis unificada [...] la situación etnográfica se define no sólo por la sociedad nativa en cuestión, sino también por la tradición etnológica «en la cabeza» del etnógrafo. Una vez que él está realmente en el campo, las presuposiciones del nativo también se vuelven operativas, y la situación completa se convierte en una mediación intercultural compleja y una experiencia interpersonal dinámica (Sholte en Okely, 1992: 1).

En nuestros días, la experiencia interpersonal dinámica a la que hace referencia Sholte se ve reflejada en los múltiples trabajos realizados por etnógrafos en cuyas narraciones se plasma magistralmente dicha interacción entre quien genera la experiencia histórica del hecho y quien logra escucharla con atención y vive de alguna manera la experiencia al sumergirse en el contexto, como la narrada por Blanca Muratorio a través de su relación con una mujer del pueblo Napu-Quichua², en donde la conexión, alimentada por las dos mujeres a lo largo de los años, se muestra en equilibrio al lograr ambas la transcendencia de sus voces: una como académica e investigadora, la otra como narradora de historias de su pueblo.

La autoetnografía genera diálogos más horizontales entre quien estudia un fenómeno desde adentro y quien lo produce. Sin embargo, en casos como el de quien esto escribe, ese diálogo constantemente oscila entre el otro y el yo, mediados por el péndulo, en donde el yo no solo observa la historia que el otro cuenta, sino que también está actuando dentro de

\footnotetext{
1 Este texto se desprende del trabajo de investigación de la tesis ¡Aquí estamos y no nos vamos! Análisis de la cultura, resiliencia y resistencia de la comunidad inmigrante latina de la ciudad de Asheville, Carolina del Norte, EE. UU., del programa de Doctorado en Antropología y Comunicación de la Universidad Rovira i Virgili. Agradezco los comentarios, las sugerencias y el acompañamiento del Dr. Juan Josep Pujadas M., quien dirige esta tesis.

2 Muratorio, B. (2005). «Historia de vida de una mujer amazónica: intersección de autobiografía, etnografía e historia». Iconos, Revista de Ciencias Sociales, 21, mayo 2005, pp. 129-143, Quito, Facultad Latinoamericana de Ciencias Sociales-Sede Académica de Ecuador. ISSN: 1390-1249.
} 
la misma, de ahí la importancia del péndulo como mediador, que, a través del viaje entre uno y otro, genera un espacio de reflexión y equilibrio. Eso podría ser la autoetnografía, la mirada del otro percibida como un espejo en donde el yo se ve reflejado - a veces con destellos, a veces transparente-, pero a la vez, ese espejo funge también como un cristal — podría decirse que cultural-, en donde el yo interpreta y construye al otro, y viceversa. El espejo convertido en cristal sería la narrativa etnográfica.

Mercedes Blanco nos dice que «la auto-etnografía amplía su concepción para dar cabida tanto a los relatos personales y autobiográficos como a las experiencias del etnógrafo como investigador - ya sea de manera separada o combinada- situados en un contexto social y cultural» (Blanco, 2012); mientras que Joaquín Guerrero opina que «la auto-etnografía es un recurso novedoso tanto en la investigación básica como en la aplicada, que está contribuyendo a generar enriquecedores debates acerca de la construcción del conocimiento en las ciencias humanas y sociales» (Guerrero, 2014: 237). Sin embargo, aún en nuestros días, existen voces que desde el positivismo descartan estos métodos en la antropología al considerarlos carentes de rigor científico (Pujadas, 2000; Blanco, 2012; Guerrero, 2014), atribuyéndoles la pérdida del equilibrio y de la objetividad al narrar desde adentro.

No obstante, el presente trabajo considera la autoetnografía como método para el análisis y la reflexión sobre el tema de la inmigración, y se apega a las ventajas que Joaquín Guerrero retoma de Heewon Chang en su libro Autoethnography as method, publicado en el año 2008, las cuales nos dicen que 1) la principal fuente de datos es el propio investigador, 2) el autoetnógrafo es un «etnógrafo privilegiado» que tiene acceso a datos familiares e íntimos, 3) la autoetnografía es de fácil lectura, por lo que es compresible para el potencial lector, 4) la autoetnografía permite una comprensión de uno mismo y de los demás, 5) la autoetnografía nos transforma y transforma a los demás, y 6) la autoetnografía permite abandonar ciertos convencionalismos metodológicos (Chang en Guerrero, 2014: 241).

Todos estos puntos dan sentido y claridad a quien desea que la praxis entre la teoría y la acción intersecte y enriquezca el discurso narrativo an- 
tropológico, sin pretender con ello obtener el protagonismo o anteponer $\mathrm{su}$ voz sobre las voces generadoras al construir dicha narrativa, lo cual puede resultar todo un reto, ya que el tener el poder de las palabras es algo que a cualquiera enajena. Sin embargo, el recurso que nos proporcionan las herramientas para la crítica, el análisis y la reflexión de la misma autoetnografía nos permite mantener el equilibrio y la objetividad en el discurso, apuntalando así su cientificidad. El mismo Joaquín Guerrero nos sugiere algunas claves metodológicas a tomar en cuenta a la hora de hacer autoetnografía: a) mantener el equilibrio en el contenido, en el proceso de investigación y en el análisis de la información, b) triangulación de fuentes, c) descripción fiel de las condiciones de la investigación y de todas aquellas variables relacionadas con la «ecuación personal», d) es necesaria la autoevaluación, e) la memoria debe estar apoyada por otros instrumentos, técnicas y fuentes que permitan completar y verificar el sentido de los hechos o experiencias, y por último, f) los significados culturales de los pensamientos y comportamientos verbal y no verbal deben interpretarse en el contexto cultural de uno mismo (Guerrero, 2014: 239-240).

Además, Mercedes Blanco sugiere que «es necesario producir textos que, precisamente, han de ser elaborados echando mano de algunas estrategias literarias» (Blanco, 2012). Estas estrategias literarias enriquecen las narraciones etnográficas, las cuales pueden convertir un texto científico en una lectura digerible y agradable.

Por lo tanto, es pertinente aclarar que en este escrito no pretendo comparar mi situación de inmigrante documentada con la de aquellas personas que también han migrado arriesgando la vida misma al tratar de conseguir mejores oportunidades, y cuya situación irregular las vulnera constantemente bajo el fantasma de la deportación. La pretensión a través de la narrativa es evidenciar el clasismo y el racismo que subyace en Estados Unidos - país que alardea de ser de inmigrantes- y cómo se sujeta la movilidad/inmovilidad de las personas al entrar y permanecer en él. Estando inmersa en el fenómeno, la autoetnografía se presenta como el recurso idóneo para analizar, criticar y reflexionar desde la plataforma antropológica con una perspectiva clara y objetiva, ya que, en palabras de H. Chang, «la auto-etnografía tiene ventajas al tener al in- 
vestigador como principal fuente de información» (Chang en Guerrero, 2014). Además, al ser activista dentro del movimiento por los derechos de los inmigrantes en la ciudad de Asheville, la ventaja se incrementa, permitiéndome escuchar las voces de todas aquellas personas involucradas en dicho movimiento - inmigrantes y sus descendientes, activistas, aliados y hasta detractores-, dando la oportunidad de tener acceso a datos más íntimos y reflexivos (Chang en Guerrero, 2014), así como a realidades más palpables y, por lo tanto, más próximas y veraces, cumpliendo con requisitos que la ciencia demanda.

Los procesos que envuelven el movimiento proinmigrante, tanto en Asheville como en muchas ciudades a lo largo y ancho de Estados Unidos, están estratégicamente creados para que la participación de todos los involucrados sea horizontal y equitativa, lo cual pone de lado al ego y otras actitudes que denotan superioridad y que muchas veces están presentes dentro de la antropología y en la misma autoetnografía - este es uno de los puntos que utilizan quienes la critican- No obstante, el reconocerme como persona inmigrante, con la necesidad de ser aceptada y de compartir mis identidades culturales desde mi posición, me ha llevado a crear relaciones honestas, abiertas y transparentes con aquellas personas para quienes el migrar ha sido una forma — quizá la única-de supervivencia. La ventaja de ver el fenómeno migratorio desde adentro, de compartir experiencias cara a cara y de escuchar largas y enriquecedoras historias de vida ha calmado al ego que normalmente acompaña a quienes hemos recorrido el camino de la educación formal - la cual genera conocimientos desde su perspectiva jerárquica y vertical-, sin embargo, como bien dice Blanca Muratorio, «al hacer historia oral, aprender a escuchar, incluyendo una detenida atención a los silencios, supone en buena medida una renuncia al ego» (Muratorio, 2005), enriqueciendo con esto la narración y, por tanto, el quehacer antropológico. 


\section{Algunos apuntes sobre el tema de la inmigración en Estados unidos y los conceptos de movilidad e inmovilidad}

Mucho se ha escrito en las ciencias sociales y humanas sobre la inmigración en los Estados Unidos de Norteamérica, desde el registro histórico de las primeras inmigraciones que dieron lugar a la formación de lo que es hoy ese país (Zinn, 2011), siguiendo con la Escuela de Chicago y los estudios realizados sobre este tema en los años veinte (Hannerz, 1986; Pérez 2002), pasando por las teorías relacionadas con la asimilación y la americanización (Gillette y Reinhardt en Pérez, 2002), como lo es el Melting Pot (Glazer y Moynihan, 1970), y los posteriores debates y refutaciones a esta teoría (Giménez, 2007: 189). La angloconformidad (Kymlicka, 1996) y su agresiva imposición del american way of life en los grupos que Will Kymlicka denomina como poliétnicos (19963); hasta bastos escritos periodísticos y académicos en donde se analiza y se reflexiona sobre la inmigración reciente, principalmente la proveniente de México y Centroamérica, y la situación política antiinmigrante impulsada desde el discurso racista y xenófobo del presidente, Donald Trump.

En la actualidad, uno de los principales estudiosos en el tema migratorio en Estados Unidos es el sociólogo Alejandro Portes ${ }^{4}$, catedrático en las universidades de Princeton y Miami, cuyos trabajos están principalmente enfocados en los inmigrantes de origen latino sin documentos y sus descendientes nacidos en Estados Unidos, y por lo tanto, ciudadanos de ese país. Además de Portes, muchos otros científicos sociales, desde las plataformas universitarias estadounidenses y latinoamericanas, están abordando - ahora más que nunca- el fenómeno de la inmigración latinoamericana, pero sobre todo mexicana, en Estados Unidos. Cada vez son más los centros universitarios que están involucrados en el tema de la inmigración en ese país y trabajando más de cerca con las comunidades de migrantes, no solo para generar ciencia social, sino para construir con esas comunidades relaciones más humanas, de apoyo y conciencia. Tal es

3 Kymlicka, W. (1996). Ciudadanía multicultural. Barcelona: Paidós.

4 Portes, A. y Rumbaut, R. (2010). Legados: la historia de la segunda generación inmigrante. Barcelona: Hipatia.

Portes, A. (2010). América inmigrante. Barcelona: Anthropos. 
el caso de la Universidad de Carolina del Norte, en Chapel Hill, que opera «The Latino Migration Project» (El Proyecto de Migración Latina), el cual se muestra como un soporte de denuncia en contra de las leyes y políticas antiinmigrantes que operan en el estado de Carolina del Norte, logrando conectar con los principales líderes de organizaciones que luchan por los derechos de los inmigrantes en ese estado, con el propósito de crear mejores estrategias que fortalezcan el movimiento por los derechos de los inmigrantes.

Por otro lado, a nivel global, el discurso académico se encuentra en una continua búsqueda de teorías, conceptos y marcos teóricos que unifiquen el análisis de la movilidad humana. De tal manera que conceptos como el de movilidad e inmovilidad y los regímenes de movilidad (Shamir, 2005) se encuentran alimentando el debate académico. Miriam Gutekunsa y otros autores (2016), en el libro Bounded Mobilities, exploran los conceptos de movilidad limitada y el de in/movilidad (Gutekunsa et al., 2016), este último lo defienden analizando que la movilidad y la inmovilidad no son dos partes de una misma cosa, sino que son la cosa en sí, y están tan estrechamente ligadas que es difícil separarlas. Sin embargo, tanto para Gutekunsa y compañía (2016) como para Glick Shiller y Salazar (2013), uno y otro enfoque están sujetos a factores como clase, etnia, identidad (Glick Schiller y Salazar, 2013; Shamir, 2005), género (Mckenzie, 2017), ideología y religiosidad. Yo agregaría el factor de la edad, el cual me parece pertinente en un análisis de migración transfronteriza y de lucha por los derechos de los inmigrantes. En el año 2014 Estados Unidos se vio desbordado por la llegada a sus fronteras de una ola de niños y jóvenes menores de dieciocho años no acompañados provenientes de Centroamérica ${ }^{67}$. En ese entonces miles de niños fueron resguardados en los centros de acogida, empujando al Gobierno de Barak Obama a crear el «Programa de Permisos Humanitarios para Menores Centroamericanos», el mismo que fue suspendido por el presidente Donald Trump en el año 2017. Los niños

$\overline{5<\text { https://migration.unc.edu/>. }}$

6 Jaime Gonzáles, 21 de junio de 2014. BBC Mundo. Recuperado en: <http://www.bbc.com/mundo/ noticias/2014/06/140620_eeuu_crisis_humanitaria_menores_indocumentados_jg>.

7 Algunos de estos que viven en Asheville aún tienen procesos abiertos en la corte de Charlotte, esperando la resolución. 
migrantes en la era de Trump funcionan también como medio para la manipulación y control de la movilidad de sus padres y madres.

Todos los seres humanos nos encontramos sujetos a la in/movilidad de acuerdo con el régimen del país en donde nos encontremos. Para las personas en movimiento transfronterizo, etnia, clase, género y edad definirán cómo y en qué condiciones se realizará esa movilidad y en qué tiempo se hará: mientras una persona cruza un puente entre la frontera México-Estados Unidos todos los días para estudiar, otra persona, tratando de cruzar en ese mismo punto, pero sin documentos, puede quedar largo tiempo inmovilizada en un centro de detención fronterizo o esperando a que haya una mejor oportunidad para cruzar. Y si esa persona logra cruzar sin ser detenida, llegar al lugar deseado, establecerse y reconformar sus redes sociales y familiares, seguramente permanecerá largo tiempo bajo movilidad limitada (Gutekunsa et alii, 2016) debido a su estatus migratorio. La amenaza de ser detenido y deportado estará siempre latente.

Por otro lado, Elena Bougleux (2016) refiere que aquella movilidad que no se limita, que no se sujeta a regímenes controladores, es activista, y le atribuye un «poder transformador» (Bougleux, 2016). Y agrega que las personas en condición in/móvil tienen la oportunidad de romper con estructuras impuestas por el capitalismo «a medida que las estructuras de poder continúan desplazando a las personas, estas personas también son capaces de desplazar estructuras de poder a lo largo de su camino» (Bougleux, 2016: 15). Eso les posibilita a crear nuevas identidades, nuevas maneras de organización que sean transformadoras, y ese es el reto al que se enfrenta el movimiento proinmigrante y de justicia social en Asheville: al generar espacios de discusión y reflexión de las realidades circundantes y sobre todo la intrínseca, se pretende construir una identidad colectiva (Giménez, 2007) apegada a la justicia social, empática a las injusticias sufridas por otros grupos, a través de la reflexión, el análisis y la crítica a los sistemas opresores y controladores, como lo es el sistema capitalista. 


\section{La migración en primera persona}

En el año 2013 y tras una vida inquietante en el México violentado por la guerra contra el narcotráfico, mi esposo y yo nos vimos en la necesidad de mudarnos a Estados Unidos animados por lo que parecía ser un Gobierno inclusivo y proinmigrante bajo el mandato de Barak Obama, lo cual poco a poco nos fue desmotivando al ir desvelando su verdadera cara conforme nos fuimos involucrando con el papeleo para obtener el visado y la residencia. Según el Servicio de Inmigración y Control de Aduanas de Estados Unidos, durante el Gobierno de Obama —de 2008 a 2016- se deportó a más de 3.434.571 personas ${ }^{8}$, lo que significa que se trata de la presidencia bajo la cual se han realizado más deportaciones a lo largo de la historia de ese país.

Las vicisitudes y los trastabilleos burocráticos para poder obtener el visado y la posterior tarjeta de residencia permanente (la famosa y muy deseada Green card) casi me hacen renunciar a continuar con los trámites, sin embargo, decidí seguir a sabiendas de que con esta tarjeta es posible trabajar e incursionar a través del número de seguro social y recibir los beneficios sociales que brinda el Gobierno de Estados Unidos. Para conseguirla presenté la documentación casi con un año de antelación hasta su obtención en las oficinas del consulado, en las oficinas del Servicio de Ciudadanía e Inmigración de Estados Unidos en Ciudad Juárez, Chihuahua. Los gastos realizados (pagos por la petición, envíos de documentos, pagos por revisión médica, traslado y estancia en Ciudad Juárez, entre otros) ascendieron aproximadamente a cinco mil dólares, que para quien, como yo, generaba en ese entonces ingresos en pesos mexicanos representaba una pequeña fortuna. Sin embargo, no hay duda de que para muchas personas el precio que tienen que pagar para entrar en Estados Unidos, con documentos o sin ellos, es mucho más elevado.

Todos estos gastos los realicé sin tener la plena certeza de que obtendría la tarjeta, aunque en el fondo sabía que era casi imposible que me la negaran. Mi estatus podía darme esa cuasi tranquilidad: mi esposo, ciudadano estadounidense, artista, egresado de la Universidad de Madi-

812 de diciembre de 2017, U.S. Immigration and Enforcement. FY 2016 ICE Immigration Removals. Recuperado de: <https:/www.ice.gov/removal-statistics/2016\#wcm-survey-target-id>. 
son, Wisconsin; mi suegro, también ciudadano estadounidense y quien fungió como mi tutor mostrando su estado de cuenta bancaria, profesor de una universidad en Missouri; y yo, profesora en una universidad de San Cristóbal de Las Casas, Chiapas, lugar donde residía. En ese año 2013 se registraron 12,5 millones de peticiones de personas de todo el mundo para el «Programa de Visas de Diversidad para Inmigrantes» — conocido como la lotería de las visas-, solo 55.000 la obtuvieron mediante este medio9. Cabe aclarar que este no es el único programa que otorga la Tarjeta verde, en total, cada año se dan alrededor de un millón de tarjetas permanentes para trabajar en Estados Unidos. Yo la recibí por parentesco.

No obstante, el mismo día en que realicé la entrevista para obtener el permiso de residencia había cientos de personas buscando obtener lo mismo que yo, por lo que pude observar, intuyo que a muchas de ellas - si no es que a la gran mayoría - el permiso les fue negado. Había incluso quienes lo habían intentado tres o cuatro veces, obteniendo el mismo resultado: «rechazado». Es muy seguro que algunas de estas personas buscaban la oportunidad de trabajar en Estados Unidos sin la intención de quedarse permanentemente, solo para hacer dinero y aspirar a tener una mejor calidad de vida para ellas y sus familias en México. Otras tantas buscaban reunirse con sus familiares: esposos, padres, madres, hijos, abuelos; se encontraban también personas que habían sido deportadas de Estados Unidos por no tener papeles, y su deseo era regularizar su situación y poder regresar a establecerse en el país que reconocían y consideraban como suyo por el hecho de haber sido llevados desde pequeños y haber crecido ahí, pero ahora, ese país, su país, les negaba ese reconocimiento. Otras tantas como Celia, la mujer que conocí en Ciudad Juárez haciendo los mismos trámites que yo, que buscaba reunirse con su hija, a la que había dejado en San José, California, cuando ella había tenido que regresar a Michoacán con sus dos hijos pequeños porque su esposo había sido deportado. En ese entonces, buscaba con desesperación la residencia permanente para estar con su hija y poder llevarse a sus hijos con ella porque uno de ellos había sido amenazado de muerte por uno de los cárteles de la droga de Michoacán. A Celia le fue negada la residencia.

95 de junio de 2018. United States of America Green Card Lottery. Official US Government Program. Recuperado de la página: <http://www.usadiversitylottery.com/es/>. 
En pleno siglo xxi y en el boom de la globalización, parece ser que solo las ideas, los capitales y quienes los poseen pueden ser parte de la movilización que brindan los tiempos modernos (Glick Schiller y Salazar, 2013; Appadurai, 1990), y para el caso de quienes, como yo, logran acceder a esa movilidad, esta se ve controlada y restringida de alguna manera también. Al recibir el visado y la carta de autorización para la tarjeta verde me sumergí en una serie de sentimientos contradictorios: ¿por qué a Celia, para quien vivir en Estados Unidos representa la supervivencia de ella y de su familia, le fue negado el visado, y por qué a mí me fue concedido, aún cuando mi situación familiar no se visualiza como apremiante o amenazada? Es muy claro que, ante este cuestionamiento, la movilidad se vuelve un asunto ligado a la clase, a la etnia y a la economía (Glick Schiller y Salazar, 2013), y sobre esto se decide quién entra y cómo a un determinado país:

¿Quién podía cruzar el puente? Yo podía cruzar el puente porque mi mamá nos había tenido del otro lado, a mí y a mi hermana. Mi mamá había tenido una visa transfronteriza y a las dos nos tuvo allá del otro lado. Y cuando cruzaba para ir a la escuela - fui primaria y secundaria-, toda mi escuela fue en los Estados Unidos, veíamos a bastantes personas cruzando o arriba del tren o en el río y entonces nos tocaba ver como que a la gente nadando, tratando de cruzar al otro lado [...] Crecí con bastante privilegio económico. Mis abuelos tenían una casa de cambio, mi abuelito tenía ranchos, mi mamá tenía ranchos, entonces crecí con bastante dinero, no sé si para el mundo, pero para Matamoros sí (V. A. México-estadounidense. Asheville, Carolina del Norte, $\left.2017^{10}\right)$.

No obstante, a quienes se encuentran en la mayor vulnerabilidad, como Celia, en situación de violencia y pobreza (consecuencias de la hegemonía del capitalismo globalizado), el sistema que controla las fronteras les ubica en la situación más inerme del estrato social, en donde su movilidad es restringida y de alguna manera, también, amenazada:

10 Debido a la política de criminalización de la inmigración del presidente Donald Trump, se opta por escribir solo las iniciales de las personas que brindaron información para la realización de este trabajo de investigación. 
[...] me paré en la puerta y dije: «¡Dios bendito! ¿A dónde me vine a meter?». Estaba ya arrepentida de haber dejado a mis padres, a mija, a mi pueblo [...] yo dije: «¡No, Dios mío!, yo creo que aquí algo va a pasar». Como que tenía el presentimiento que algo estaba mal acá [...] desgraciadamente sí era lo que yo esperaba porque había muchas muchachas que con tal de que las cruzaran para Estados Unidos, muchos de los hombres encargados que cruzaban [sic] abusaban de ellas, las violaban, básicamente. Había niñitas de cuatro, cinco años, siete años [...] había una niña de diez años haciéndole caricias a un hombre. Yo decía: «iEso no puede ser!, ¡no está bien!», pero ella también, con la idea de que iba a ver a su mamá (T. P. Mexicana. Asheville, Carolina del Norte, 2017).

Sin embargo, aun ante este tipo de amenazas, su movilidad no está bloqueada, ya que se apegan al instinto humano de subsistir, por lo que, aún cuando el sistema les limita la esperanza de una vida mejor, la gente emigra buscando ese bienestar por encima de leyes, acuerdos internacionales o posicionamientos políticos e ideológicos de la Administración de turno (estas personas que enfrentan y retan estos límites Elena Bougleux [2016] las denomina activistas). La mayoría de las historias que me han sido compartidas acreditan la mejora familiar, al menos en lo económico, aunque esto conlleva una serie de abusos, explotaciones y vejaciones en casi todos los ámbitos, amén de las leyes migratorias que representan casi siempre una amenaza para quienes no cuentan con documentos que acrediten la residencia legal. Carolina del Norte es uno de los estados con más leyes antiinmigrantes que hay en Estados Unidos. Tan solo en lo que va del año 2018, la Asamblea Legislativa de ese estado, de mayoría republicana, tiene en la lista de discusión una serie de propuestas de ley en las cuales se quebranta aún más la situación del trabajador inmigrante sin documentos ${ }^{11}$.

Se podría decir que el cómo, el porqué y el para qué se migra de un país como México hacia Estados Unidos depende de las situaciones sociales, económicas, de género (Mckenzie, 2017) y étnicas de quien decide

11 Karina Neyra, 3 de enero de 2018. «Proyectos de ley en NC que en 2018 amenazarán a inmigrantes». Qué Pasa.

$<$ https://raleigh.quepasanoticias.com/noticias/carolina-del-norte/proyectos-de-ley-en-nc-que-en2018-amenazaran-a-inmigrantes $>$. 
emprender el camino. En el cómo se emigra se manifiestan claramente estos estatus: quien más privilegios posea arriesgará menos al cruzar la frontera. Es muy probable que la residencia se me otorgase porque no represento, ante la mirada del sistema estadounidense, ningún peligro, $\mathrm{y}$ mucho menos una carga: soy una mujer educada formalmente, sin hijos, jamás había estado en Estados Unidos, mi familia no depende de mí y estoy bajo la tutela, no de uno, sino de dos hombres blancos estadounidenses económicamente estables —esta última podría ser la razón de mayor peso- - Celia, por otro lado, ya había estado viviendo sin documentos en Estados Unidos junto con su esposo - sus hijos son la prueba, nacieron allí-. Provienen de una zona rural de Michoacán, en donde se dedicaban a la agricultura y en donde casi no tuvieron acceso a estudios. Durante los más de quince años que vivieron en Estados Unidos trabajaron en el área de servicios, ella como camarera y él como jardinero. Su esposo fue deportado en tres ocasiones, en la última recibió la amenaza de que si lo volvían a detener por no tener documentos lo procesarían por un crimen mayor, por lo que decidió permanecer mejor en México. Celia nunca fue deportada, sin embargo, en ese entonces decidió seguir a su esposo, llevando consigo a sus pequeños hijos de nacionalidad estadounidense, dejando a su hija mayor del otro lado para que terminara los estudios que la preparan para entrar a la universidad. Celia no quiere pasar más a Estados Unidos como indocumentada, la última vez que lo hizo casi pierde la vida, no obstante, quiere estar con su hija y llevarse a sus hijos con ella, lejos de la violencia del narcotráfico. Ahora le toca esperar y volverlo a intentar hasta obtener la residencia.

El porqué de emigrar recae, en muchos de los casos, en la situación de pobreza, marginación y violencia de todo tipo que se vive cotidianamente en los países del Tercer Mundo. Un buen porcentaje de la migración latina en Asheville proviene de los estados mexicanos de Michoacán, Puebla, Hidalgo, Estado de México y Morelos, principalmente de las zonas rurales. De acuerdo con Jorge Durand (2007), solo el primero está catalogado en la región histórica, región que tradicionalmente ha expulsado mano de obra barata hacia Estados Unidos. Los estados restantes pertenecen a la región central (Durand, 2007), en donde el cultivo del maíz y de otros gra- 
nos eran fuente importante de ingresos; sin embargo, se encontraron en situación bastante desfavorecida después de la firma del Tratado de Libre Comercio de América del Norte, acordado por Canadá, Estados Unidos y México, debido a la eliminación paulatina de los aranceles de los productos del campo que provienen de Estados Unidos (Puyana y Romero, 2011), afectando principalmente al campo mexicano:

En el 96 después de los tratados de NAFTA ${ }^{12}$, hubo un gran éxodo de personas de México hacia acá, y pues mi pueblo no fue la excepción porque muchos de los comerciantes se vieron afectados por las nuevas regulaciones de libre comercio. [...] En ese tiempo mi hermano trabajaba en la Central de Abastos $^{13}$ y la Central de Abastos cayó muy feo (P. D. Mexicana. Asheville, 2017).

De la misma manera, muchos de los inmigrantes centroamericanos que residen en Asheville llegaron huyendo de la violencia generada por las luchas internas de sus países de origen, las cuales en muchas ocasiones fueron avivadas o de alguna manera alimentadas por la política entrometida de Estados Unidos (Zinn, 2011).

Aunque el para qué resultaría un poco más abstracto al abrir el abanico del futuro que se busca al emigrar, ya que cada individuo «sigue sus imaginaciones, en el sentido de que Arjun Appadurai denota esta poderosa fuerza de los sueños» (Götz, 2016: 9). No obstante, y sin lugar a dudas, el abanico parte de la posibilidad de tener mejores oportunidades que permitan alcanzar el bienestar familiar, tanto para la familia que se deja en México como la que se construye en Estados Unidos.

Yo me siento agradecida con Dios y con el país porque habemos tantos inmigrantes que queremos llegar a este país con bien y desafortunadamente no todos lo logramos. Y creo que el estar aquí es una bendición porque tenemos más comodidad que estar en nuestro país, y precisamente por eso, creo que mucha gente emigramos para acá para tener un mejor futuro y una mejor vida (S. M. Mexicana. Asheville, 2017).

12 North American Free Trade Agreement.

13 La Central de Abastos es el mercado principal y mayor centro de distribución de víveres en Ciudad de México. 
Según el Anuario de Migración y Remesas de México del año 2016, Estados Unidos se posiciona como uno de los principales países de emisiones de remesas en el mundo, mientras que México es el cuarto receptor mundial, antecedido solo por India, China y Filipinas, lo que para el país latinoamericano representa el $2,3 \%$ del $\mathrm{PIB}^{14}$, el cual muy probablemente se refleja en el bienestar social de las familias receptoras. En mi experiencia, el envío de dinero a mi familia en México permitió que mi madre recibiera mejor atención médica para sus problemas de salud.

En Asheville, la constitución de muchas familias de origen mexicano o latinoamericano es más o menos de reciente formación, los hijos mayores nacidos en Estados Unidos difícilmente tienen más de veinte años, el mayor porcentaje de los migrantes llegaron a Carolina del Norte a finales de los años noventa y durante los años dos mil, y casi en proporciones de género similares y en rangos de edades parecidas ${ }^{15}$. Muchas de estas familias tienen como característica estar formadas por padres y madres de entre treinta y cuarenta años y por hijos adolescentes, niños y bebés. También hay familias completas o parte de ellas que emigraron juntas desde otras regiones de Estados Unidos y unas más desde sus lugares de origen, con o sin documentos. Para estos padres y madres, el permanecer en este país es sinónimo de poder ofrecer a sus hijos mejores oportunidades en la vida, y como en el caso de las personas que vienen huyendo de la violencia de México y Centroamérica, representa la conservación de la vida misma:

Creo que sí ha valido la pena porque donde nosotros vivíamos había mucha inseguridad y ahora la vida de mis hijos ha cambiado totalmente pero para bien. Incluso creo que han tenido mayor oportunidad para salir adelante aquí que allá. Aquí me puedo dormir y saber que van a estar bien y allá no podía ni pegar el ojo porque se escuchaban las balaceras afuera de mi casa, ya habían secuestrado y matado a un chavito. Estaba horrible (C. R. Mexicana. Asheville, 2017).

14 Anuario de Migración y Remesas, México 2016. Secretaría de Gobernación. Recuperado en: <https:// www.gob.mx/cms/uploads/attachment/file/109457/Anuario_Migracion_y_Remesas_2016.pdf>. 15 Ídem. 
Para mí también valió la pena porque en El Salvador todos los días tenía que andar corriendo, estar huyendo, esconderme [sic]. Ver cosas que ni siquiera en mi loca imaginación podía pensar que tenía que ver. Y venir aquí es como sentir paz, aunque andas huyendo no es ese tipo de peligro, con ese miedo. Es muy diferente. Aquí me siento más seguro que en mi país (O. D. Salvadoreño. Asheville, 2017).

Como se ha mencionado, en Asheville, como en muchas ciudades del estado de Carolina del Norte, la inmigración es más o menos reciente (Zúñiga, Leite y Nava, 2004) y por lo tanto, las familias aún son jóvenes, la desesperanza y frustración que aparecen después de muchos años como resultado de la emigración aún no son percibidas en gran manera aquí como en otros lugares de Estados Unidos ${ }^{16}$, aunque empiezan a aparecer esos rasgos debido a la amenaza constante de la separación familiar y de otras injusticias que suceden alrededor. De ahí la importancia de fortalecer los movimientos de justicia social y, en este caso, el ligado a los derechos de los inmigrantes, porque de acuerdo con los líderes de este movimiento en Asheville, uno de los objetivos del mismo es tener una comunidad sana y estable, pero esto solo se conseguirá a través de la resistencia y de la lucha organizada. Es, por lo tanto, la oportunidad de crear nuevas identidades transformadoras (Bougleux, 2006).

\section{Activismo, cultura y resistencia: el movimiento proinmi- grante en Asheville}

Como se ha dicho, tras la apertura del Tratado de Libre Comercio de América del Norte en 1994, muchas personas en México se vieron en la necesidad de salir de sus comunidades y emigrar hacia las grandes ciudades del país o hacia Estados Unidos. Esto coincidió con el crecimiento económico que empezaba a vislumbrarse desde los años ochenta en Carolina del Norte (Durand, 2007) y bajo el desarrollo del Cinturón del Sol (Sun Belt) (Sandoval, 2005: 20), el cual demandaba mano de obra barata para la construcción de edificios que albergarían las oficinas bancarias (Char-

16 Ídem. 
lotte, la ciudad más grande del estado, es el segundo centro bancario de Estados Unidos) y de desarrollo turístico.

Mi papá primero llegó a California y después se vinieron a Asheville a Carolina del Norte con mis otros tíos. Mi papá vino siguiendo a mis tíos y mis tíos se vinieron por un amigo aquí a Carolina del Norte, eran amigos desde México y les dijo que aquí se estaba muy bien. Trabajaban juntos con mi papá en el hotel. Y creo que sí, en parte se vinieron aquí a Carolina del Norte por el boom de la construcción (H. B. Mexicano. Asheville, 2017).

Asheville, Carolina del Norte, es una ciudad ubicada en la cadena montañosa de los Apalaches y cuenta con 89.121 habitantes, de los cuales, según el Buró de Censo de Estados Unidos a 1 de julio de 2016, el 5,7\% de la población total son latinos o hispanos ${ }^{17}$.

Conforme este censo, la población de origen hispano creció en Carolina del Norte del 1,2\% en 1990, al 4,7\% en 2000 , y al 8,8\% (867.205 personas) en 2013 . El área que más ha demandado mano de obra barata aportada por los inmigrantes es la de la construcción, aunque existen regiones agrícolas en donde se concentra también la mano de obra «para las cosechas y la industria avícola» (Durand, 2007: 74). Asheville se ha convertido en la actualidad en un lugar de moda, atrayendo a turistas tanto nacionales como extranjeros, ya que cuenta con el privilegio de estar rodeada de la belleza natural de las montañas Apalaches y del Parque Nacional de las Grandes Montañas Humeantes. Además, Asheville ha destacado también por su producción de cerveza artesanal, sin embargo, esta ha empezado a ser absorbida por las grandes compañías nacionales cerveceras, la última de estas cervecerías en instalarse en esa ciudad ha sido New Belgium Brewing, logrando con esto que Asheville aparezca en el top-ten de la lista de Beer City USA, lo cual también la vuelve atractiva para el turismo. Todo esto ha hecho que esta ciudad requiera incrementar su oferta de servicios turísticos para la cual la comunidad inmigrante latina, documentada o no, contribuye en gran medida, y va desde la construcción y remodela-

17 2016. USA Census Bureau. Asheville City, North Carolina. Recuperado en: <https://www.census. gov/quickfacts/fact/table/ashevillecitynorthcarolina/PST045216>. 
ción de hoteles, casas y restaurantes, hasta el mantenimiento, cuidado y limpieza de los mismos.

Aunque laboralmente la población latina de Asheville se concentra en las áreas antes mencionadas, lo cierto es que actualmente la actividad económica de esta población se ha extendido mucho más allá, y han pasado de ser empleados dependientes a ser autónomos, no han temido invertir en sus propios negocios, lo cual también genera empleos para la comunidad. En Asheville existen muchos comercios latinos que van desde supermercados, tiendas de ultramarinos, peluquerías, estéticas de belleza, talleres de servicios automecánicos, restaurantes - muchos- de comida mexicana, salvadoreña, hondureña, peruana; así como todos los servicios relacionados con la organización de fiestas como la de los quince años, bautizos, bodas y primeras comuniones ${ }^{18}$.

A través de las redes familiares, de paisanos o de amigos, la comunidad latina de Asheville se apoya económicamente y es difícil encontrar en esa ciudad y en todo el condado de Buncombe gente inmigrante que no tenga algún tipo de empleo. Y esto, como se mencionó anteriormente, es probable que se deba a que la inmigración latina en el estado de Carolina del Norte, y más concretamente la de Asheville, es prácticamente reciente. Además, parece ser que el estado sigue demandando mano de obra, ya que, según la revista Forbes, en 2017 Carolina del Norte se perfiló como el mejor estado para hacer negocios en Estados Unidos: «Con una de las tasas más altas de migración neta en los EE. UU., la gente ha acudido en masa a Carolina del Norte durante la última década. El estado tiene la segunda fuerza laboral sindical más pequeña en los EE. UU., en términos de porcentaje del empleo total (Carolina del Sur es la primera). El beneficio resultante son los costos de mano de obra que están un 10\% por debajo del promedio nacional, el quinto más bajo en el país» (Forbes, $2018^{19}$ ). A esto hay que sumarle los bajos impuestos que las grandes compañías pagan al estado.

18 La religión católica predomina entre esta población.

19 Forbes, 2018. «Best States for Business». Recuperado en <https://www.forbes.com/best-states-forbusiness/list/>. 
Así, en el principio, Carolina del Norte y sus principales ciudades parecieron ser el paraíso de la inmigración atraída por el crecimiento económico y la demanda de la mano de obra barata.

Entonces, cuando empecé [a trabajar en Asheville], ya había pasado el boom de los 2000 en el que había llegado un montón de gente a ayudar a que Carolina del Norte creciera, había llegado mucha gente a la construcción [a trabajar], entonces cuando yo llegué era algo así como Shangri-la (V. A. México-estadounidense. Asheville, 2017).

Con el paso del tiempo, esta relación se ha ido tornando más abusiva, amenazante y explotadora en contra de l@s inmigrantes, sobre todo de aquell@s que no lograron regularizar su situación migratoria antes de 2006, año en que se dejaron de otorgar las licencias para conducir a inmigrantes sin documentos y en el que empezaron a realizarse retenes de revisión de licencias ${ }^{20}$ por parte de las policías de los condados - por lo que la movilidad de la comunidad se ha visto grandemente afectada-, razón principal por la que en el oeste de Carolina del Norte comenzaron a surgir los centros comunitarios y organizaciones en defensa de sus derechos.

Y la ciudad de Asheville no fue la excepción, en el año 2007 se creo Nuestro Centro y poco antes se habían creado el Centro para Cambios Participativos y la Coalición de Organizaciones Latinas, que en la actualidad es Compañeros Inmigrantes de las Montañas en Acción (CIMA).

Nuestro Centro es una organización sin fines de lucro que atiende directa y completamente en español a la comunidad latina de la ciudad de Asheville, pero sobre todo, la que se ubica en el barrio de Emma, en el cual se encuentra concentrada una buena parte de la población inmigrada que en su mayoría son mexicanos, aunque también residen personas de Cen-

20 Esto es la excusa para detener a personas inmigrantes porque en muchas ocasiones los retenes se colocan en las entradas de los vecindarios latinos, incluso, ha habido ocasiones en que los retenes se han puesto en las entradas de las escuelas del barrio de Emma, barrio predominantemente latino en Asheville, y aunque en Carolina del Norte está prohibido utilizar el perfil racial para realizar detenciones, lo cierto es que personas detenidas han manifestado lo contrario:

«El policía empezó a buscar en la camioneta, que si traíamos drogas y todo eso. Esa fue una experiencia muy dura que yo tuve, pues porque no sabía yo por qué lo están parando a mi esposo [sic], qué hicimos. Y no hicimos nada, solo íbamos a cruzar la calle, no venía ningún carro. [...] Ahora que ya tengo un poco más de conocimiento, creo que fue perfil racial lo que hizo este policía porque él nos miró, y a como él nos miró [sic], luego, luego, fue atrás de nosotros» (T. P. Mexicana. Asheville, Carolina del Norte, 2017). 
tro y Sudamérica. Nuestro Centro Community Center fue fundado en el año 2007 por un grupo de mujeres de origen latino y anglo, interesadas y preocupadas por el bienestar de la comunidad inmigrante de habla hispana de Asheville.

Nuestro Centro está cimentado en los principios y valores de la educación popular ${ }^{21}$ y sus proyectos están enfocados en crear conciencia política a través de la educación y cultura de la comunidad inmigrante. Se organiza por medio de un grupo de gente — trabajadores y voluntarios-, quienes escuchan las necesidades de la comunidad, creando y coordinando los proyectos y actividades, los cuales, a su vez, son aprobados y apoyados mediante un comité central formado por gente de la misma comunidad, algunas de estas personas se ven directamente afectadas por las leyes y posturas que impactan a los inmigrantes sin documentos. La base de Nuestro Centro está conformada mayoritariamente por personas inmigrantes que no cuentan con permisos de residencia pero que están incrustadas en el área laboral y social de la ciudad de Asheville, por lo que esta organización busca brindarles un espacio para el aprendizaje colectivo, así como protección y bienestar, creando conciencia de sus derechos. Todo esto se lleva a cabo a través de talleres, reuniones, marchas, vigilias y la convivencia familiar y comunitaria, tal como fue el caso del evento «iAsheville no Trabaja, Iro de Mayo!», realizado el primero de mayo de 2017 , en el que se efectuaron una marcha y una serie de actividades enfocadas a crear conciencia sobre el aporte económico, social y cultural que la comunidad latina brinda a la ciudad de Asheville.

En sus inicios, Nuestro Centro respondía más a un modelo de consulta/referencia y de protesta, brindando apoyo y asistencia a quienes requerían servicios tales como la búsqueda de un trabajo o la solicitud de los

\footnotetext{
21 Retomaré la definición que Carlos Núñez da sobre la educación popular: «Es una propuesta teórico-práctica, siempre en construcción desde cientos de prácticas presentes en muy diversos escenarios de nuestra América (y más allá). Su visón es integral, comprometida social y políticamente. Parte y se sustenta desde una posición ética humanista. Asume una posición epistemológica de carácter dialéctico, rechazando por tanto el viejo, tradicional y todavía «consagrado» marco positivista. En consecuencia, desarrolla una propuesta metodológica, pedagógica y didáctica basada en la participación, en el diálogo, en la complementación de distintos saberes. Y todo ello desde y para una opción política que ve el mundo desde la óptica de los marginados y excluidos y que trabaja en función de su liberación», en Carlos Núñez «Educación popular: una mirada de conjunto». Instituto Tecnológico y de Estudios Superiores de Occidente, Guadalajara, México. Revista Decisio, 10, 2005.
} 
servicios que brinda la ciudad de Asheville o el condado de Buncombe. También existía el programa «Defensa Comunitaria ${ }^{22}$ », el cual se enfocaba en luchar en contra de las políticas y actos antiinmigrantes llevados a cabo por la policía de Asheville o por la del condado de Buncombe. Mediante este programa se llevaron a cabo las acciones y campañas en oposición al proceder de estas policías locales y las del Servicio de Seguridad de Estados Unidos y del Servicio de Inmigración y Control de Aduanas, por los retenes y redadas llevadas a cabo en Asheville entre los años 2008 y 2012.

La transformación de Nuestro Centro hacia un modelo más estabilizado en donde su enfoque sea más educativo, intencional y crítico ha sido paulatina y difícil, ya que la amenaza de separación de familias está siempre latente y, al parecer, desde la toma de posesión de Donald Trump como presidente de Estados Unidos, se ha tornado más violenta e injusta debido a que la nueva política migratoria criminaliza de manera contundente la inmigración indocumentada (Shamir, 2005).

Me uní a Nuestro Centro a finales del año 2013 primeramente como voluntaria y posteriormente como cocoordinadora. Mi trabajo se ha enfocado desde entonces en la cultura y en la educación política, las cuales se llevan a cabo mediante proyectos que incluyen la organización comunitaria y la realización de talleres, reuniones, eventos, etc. Sin embargo, debido a la inestabilidad de la organización - por las causas antes mencionadas-, me he visto envuelta también en la participación en acciones de respuesta rápida, como son las marchas, los boicots y las protestas. Pero al sentirme de pronto sin herramientas para apoyar al movimiento, reaccionando una y otra vez sin tener la certeza de estar creando estrategias más profundas, enfocadas e intencionales que sirvan para fortalecer el movimiento proinmigrante y de justicia social de Asheville, he tenido que volver a buscar en la ciencia, y más exactamente en la antropología, en sus bases teóricas y prácticas, las respuestas que puedan contribuir a este fortalecimiento. La fórmula: teoría-práctica-teoría, tan necesaria para llegar a la praxis, me brinda la posibilidad de generar análisis y reflexión del tema en cuestión, tomando como referencia las voces y experiencias

22 Actualmente este programa está a cargo de CIMA. 
de quienes luchan día a día demandando justicia, respeto y dignidad para los inmigrantes del oeste de Carolina del Norte y sus familias.

Es posible decir entonces que cómo se involucra Asheville en un movimiento a nivel nacional proinmigrante se debe principalmente al incremento de inmigrantes de origen latino en Carolina del Norte, y muy concretamente en esa ciudad desde los años noventa y hasta nuestros días. Esta comunidad ha ido construyendo redes vinculadas a su identidad étnica, cultural y de clase (Castells, 1999), lo que ha permitido la formación de grupos y organizaciones que reclaman sus derechos laborales y humanos. El porqué responde a la resistencia ante el abuso de poder que ejercen las élites contra los inmigrantes, sobre todo en aquellos que no cuentan con documentos legales de permanencia, quedando desprotegidos ante tal abuso, restringiendo su movilidad de manera alarmante. En el para qué involucrarse en un movimiento de tales dimensiones se encuentra ligado a cuestiones más profundas, más enraizadas, como son la cultura y la identidad de grupo, y se vincula a lo que el liberal Will Kymlicka, en su libro Ciudadanía multicultural (1996), denomina derechos poliétnicos. Es decir, el derecho que tienen los grupos de inmigrantes a reproducir su cultura en el territorio en donde residen (Kymlicka, 1996). Sin embargo, el despojo a la dignidad del inmigrante — criminalizando su estatus (Shamir, 2005) - y la deshumanización a la que se ve sujeto mediante mecanismos de control como la angloconformidad (Kymlicka, 1996) motivaron que personas de diversas etnias, religiones y clases sociales iniciaran el movimiento proinmigrante en el oeste de Carolina del Norte para reclamar los derechos de este grupo, aunque en la actualidad las bases y los líderes de muchas de estas organizaciones son ya los propios inmigrantes afectados por todas esas injusticias. 


\section{Conclusión}

La antropología, a través de la autoetnografía y de sus teorías y conceptos vinculados a los flujos migratorios transfronterizos, me ha permitido poder ver el problema de la inmigración en Asheville desde una perspectiva más objetiva. Analizar el cómo, el porqués y el para qué de los aspectos que rodean la migración en Asheville me ayuda a comprender lo que significa ser una inmigrante mexicana viviendo en Estados Unidos en la era de Trump, pero sobre todo, el ser activista y académica me reta a deconstruir mi papel dentro del movimiento proinmigrante en el oeste de Carolina del Norte. Esto me posibilita abordar el tema desde adentro, desde una óptica más cercana a la realidad, pero también me lleva a profundizar en el análisis de las políticas y regímenes nacionales y de cómo se encuentran alineados a las élites de poder y control, que son las que disparan la desigualdad y la inequidad a través de actos injustos y opresivos. Dar cuenta de esto no me deja en la desesperanza, más bien, me brinda la oportunidad de seguir impulsando el trabajo académico y acercarlo al activismo para contribuir a la efectividad del movimiento. De tal forma que evidenciar las injusticias que rodean la inmigración en Asheville y buscar las estrategias más acertadas es también tarea de la ciencia y no solo de los movimientos sociales. Tenemos, pues, en las ciencias sociales, y muy concretamente en la antropología, el gran reto de contribuir a la transformación de las poblaciones y sociedades oprimidas. 


\section{Referencias bibliográficas}

Appadurai, A. (1990). «Disjuncture and Difference in the Global Cultural Economy». Theory, Culture \& Society, 1990; 7; 295. DOI: 1177/026327690007002017.

Bougleux, E. (2016). «Im/mobilities in Subjects and Systems». En M. Gutekunsa et alii (eds.) (2016). Bounded Mobilities. Ethnographic Perspectives on Social Hierarchies and Global Inequalities. Bielefeld: Transcript Verlag. Recuperado de: <www.transcript-verlag.de/ 978-3-8376-3123-4. 12-16>.

Blanco, M. (2012). «¿Autobiografía o autoetnografía?». Desacatos, revista de ciencias sociales. CIESAS, núm. 38, enero-abril, pp. 169-178.

CAstells, M. (1999). La Era de la información, Economía, Sociedad y Cultura. Volumen II: El Poder de la Identidad. México: Siglo XXI Editores.

DurAnd, J. (2007). «Origen y destino de una migración centenaria». En M. Ariza y A. Portes (coords.). El País Transnacional: Migración Mexicana y Cambio Social a través de la Fronter, (pp. 55-81). México: Universidad Nacional Autónoma de México. Instituto de Investigaciones Sociale. GiméNEz, G. (2007). Estudios sobre la cultura y las identidades sociales. México: Consejo Nacional para las Culturas y las Artes.

Glazer, N. y Moynihan, D. (1970). Beyond the Melting Pot: The Negroes, Puerto Ricans, Jews, Italians, and Irish of New York City. Cambridge, Massachusetts: The M.I.T. Press.

Geterunsa, M. et alii (eds.) (2016). Bounded Mobilities. Ethnographic Perspectives on Social Hierarchies and Global Inequalities. Bielefeld: Transcrip Verlag. Recuperado en: <www.transcrip-verlag.de/978-38376-3123-4>.

Glick Schiller, N. y Salazar, N. (2013). «Regimes of Mobility Across the Globe». Journal of Ethnic and Migration Studies, 39(2): 183-200.

Göтz, I. (2016). «Mobility and Inmobilitie: Background of the project». En M. Getekunsa et alii. Bounded Mobilities. Ethnographic Perspectives on Social Hierarchies and Global Inequalities. Bielefeld: Transcrip Verlag. Guerrero, J. (2014). «El valor de la auto-etnografía como fuente para la investigación social: del método a la narrativa». AZARBE. Revista internacional de trabajo Socialy Bienestar, 3: 237-242. Universidad de Murcia. Recuperado en: <www.transcrip-verlag.de/978-3-8376-3123-4. 9-11>. 
HANNERZ, U. (1986). Exploración de la ciudad: hacia una antropología urbana. México: FCE.

Kymlicka, W. (1996). Ciudadanía multicultural. Barcelona: Paidós.

Mckenzie, B. (2017). «To Know a Citizen: Birthright Citizenship Documents Regimes in U.S. History». En B. N. Lawrence y J. Stevens (eds.). Citizenship in Question. Evindentiary Birthright and Statelessness (pp. 117-131). USA: Duke University Press.

Muratorio, B. (2005). «Historia de vida de una mujer amazónica: intersección de autobiografía, etnografía e historia». ICONOS, 22: 129-143. NúÑEZ, C. (2005). «Educación popular: una mirada de conjunto». Instituto Tecnológico y de Estudios Superiores de Occidente, Guadalajara, México. Revista Decisio, 10: 3-14.

Okely, J. y Callaway, H. (eds.) (1992). Anthropology and autobiagraphy. London; New York: Routledge.

PÉREZ, L. (2002). «El Desarrollo de las Investigaciones sobre Inmigración en los Estados Unidos de América». Florida International University, REDEN, 23-24.

Pujadas, J. (2000). «El método biográfico y los géneros de la memoria». Revista de Antropología Social, pp. 127-158. ISSN: 1132-558X.

Puyana, A. y Romero, J. (2011). «El sector agropecuario mexicano a diez años del TLCAN». En Movimiento Ciudadano, La Migración de Mexicanos en Estados Unidos 2000-2010: Impacto Social Económico y Político en Ambos Lados de la Frontera, Evidencias Recientes. Documento Metodológico.

SANDOVAL, J. M. (2005). «México: país-frontera. La nueva geopolítica regional de América del Norte». En J. M. Sandoval y R. Raquel Álvarez (coords.). Integración Latinoamericana, Fronteras y Migración: los casos de México y Venezuela (pp. 65-100). Universidad de Los Andes (Venezuela); Centro de Estudios Chicanos y de Fronteras, A. C.; Plaza y Valdés, S.A., México.

SHAMIR, R. (2005). «Without Borders? Notes on Globalization as a Mobility Regime». Sociological Theory, 2(23): 197-217. Recuperado en: <http:// www.jstor.org/stable/4148882>.

Scholte, B. (1974). «Toward a Reflexive and Critical Anthropology». En D. Hymes (ed.). Reinventing Anthropology. New York: Vintage Books. 
Zinn, H. (2004). A People's History of the United States: 1492 to Present. New York: Siete Cuentos Editorial.

ZÚÑIgA, E.; Leite, P. y Nava, A. (2004). La nueva era de las migraciones. Características de la migración internacional en México. México: Consejo Nacional de Población.

\section{Páginas de Internet}

Forbes (2018). «Best States for Business». Recuperado en: <https://www. forbes.com/best-states-for-business/list/>.

GonZÁles, J. (21 de junio de 2014). BBC Mundo. Recuperado en: <http:// www.bbc.com/mundo/noticias/2014/06/140620_eeuu_crisis_humanitaria_menores_indocumentados_jg>.

Harmon, A. (28 de mayo de 2018). "Did the Trump Administration Separate Immigrant Children From Parents and Lose Them?». The New York Times. Recuperado en: <https:/www.nytimes.com/2018/05/28/ us/trump-immigrant-children-lost.html>.

Neyra, K. Qué Pasa (3 de enero de 2018). «Proyectos de ley en NC que en 2018 amenazarán a inmigrantes». En: <https://raleigh.quepasanoticias.com/noticias/carolina-del-norte/proyectos-de-ley-en-nc-queen-2018-amenazaran-a-inmigrantes $>$.

Secretaría de Gobernación (2016). Anuario de Migración y Remesas, México 2016. Recuperado en: <https://www.gob.mx/cms/uploads/ attachment/file/109457/Anuario_Migracion_y_Remesas_2016.pdf>.

United States of America Green Card Lottery. (5 de junio de 2018). Official US Government Program. Recuperado de la página: <http://www.usadiversitylottery.com/es/>.

U.S. Immigration and Enforcement (12 de diciembre de 2017). FY 2016 ICE Immigration Removals. Recuperado de <https://www.ice.gov/removalstatistics/2016\#wcm-survey-target-id>.

USA Census Bureau. Asheville City, North Carolina (2016). Recuperado en: $<$ https://www.census.gov/quickfacts/fact/table/ashevillecitynorthcarolina/PST045216>. 